\title{
Cognitive changes after Carotid Endarterectomy
}

\author{
Modifiche cognitive in seguito \\ ad endarterectomia carotidea
}

\author{
Paola Gremigni ${ }^{1}$, Laura Sciarroni ${ }^{1}$, Luciano Pedrini2
}

\begin{abstract}
Cognitive changes after Carotid Endarterectomy. P. Gremigni, L. Sciarroni, L. Pedrini.

The aim of this study was to investigate changes in cognitive function following carotid endarterectomy (CEA).

In 74 asymptomatic CEA patients cognitive function, depression, laterality and severity of stenosis, cerebral Computer Tomography results, and ischemic heart diseases were measured preoperatively. The sample included 31 patients with dementia and 43 patients without any symptom of dementia. Cognitive function was measured
\end{abstract}

again at 3 months postoperatively using a brief standardised test.

After controlling for cognitive function and depression at baseline, cognitive function improved significantly at 3 months after CEA in both patients with and without dementia.

CEA may offer more than reduced stroke risk to patients, independent of cognitive function.

Keywords: carotid endarterectomy, cognitive function.

Monaldi Arch Chest Dis 2009; 72: 91-97.

1 Department of Psychology, University of Bologna, Italy.
2 Operative Unit of Vascular Surgery, Maggiore Hospital, Bologna, Italy.

Corresponding author: Dr. Luciano Pedrini; Operative Unit of Vascular Surgery, Maggiore Hospital; L.go B. Nigrisoli, 2 - I-40133 Bologna, Italy; E-mail address: luciano.pedrini@ausl.bologna.it

\section{Introduction}

Indication to carotid endarterectomy (CEA) has been defined by many trials as NASCET [1], ECST [2], ACAS [3], ACST [4], and their revisions. Results have shown a significant benefit of this treatment in the prevention of ipsilateral stroke and death; however these trials did not focused on other secondary end-point, one of which is cognitive deterioration.

Patients with carotid stenosis show a neuropsychological syndrome with decline of cognitive function and poor psychological well-being [5], but the association between carotid disease and cognitive impairment is not defined [6].

The atherosclerotic plaque can be theoretically responsible of cognitive deterioration secondary to multiple cerebral infarctions or by reducing the cerebral blood flow.

Vascular dementia and Alzheimer's disease often coexist in elderly [7]; moreover, it has recently observed that patients who suffered ischemic cerebrovascular events have greater risk of developing dementia [8]. About the second pathogenetic mechanism, it has been recently shown that cognitive impairment and decline are associated with asymptomatic high grade stenosis of the left internal carotid artery [9] CEA increased postoperative brain perfusion might improve cognition in patients with vascular dementia.
As some studies report an improvement of cognitive function, while others more recent studies do not show significant cognitive progress and few proved impairment [10-14], the role of CEA in the prevention of cognitive deterioration results controversial.

The purpose of this study is to investigate changes in cognitive function following CEA for high-degree internal carotid artery stenosis in a sample of asymptomatic patients with non-compromised cognitive function and with mild vascular dementia at baseline.

\section{Methods}

\section{Study design}

In this longitudinal study, psychological tests were performed on the day before surgery and after 3-months of follow-up. Administration of the tests few days postoperatively was not taken into consideration to avoid effects of repeated testing. Practice effects are defined as improvements in cognitive test performance due to repeated evaluation with the same test materials. Practice effects on measures of memory and learning are minimal when the testretest interval is of sufficient length. We have chosen a 3-months interval for re-testing as Falleti et al. suggest that, in designs where individuals need to be tested one-month apart, performance at this interval should reflect actual levels of cognitive ability [15]. 


\section{Patients}

One hundred consecutive patients were enrolled in this study. All patients gave informed consent or assent to the study and the research project was approved by the Hospital Medical Direction.

Indication for surgery was a carotid stenosis greater than $75 \%$ (ECST method). One patient presented a restenosis associated to a pseudo aneurysm due to the detachment of a carotid patch applied 5 years before. Patients with severe cardiac or pulmonary diseases and/or with restenosis or previous neck surgery were scheduled for carotid artery stenting (CAS) and excluded from this study. Twenty six symptomatic patients with a previous stroke and/or permanent neurological damages and severe dementia were also excluded from the study; thus 74 asymptomatic patients finally participated in the study.

The preoperative evaluation included a colourDoppler Ultrasonography of the extra cranial vessels, a brain Computer Tomography (CT) scan, the study of the intracranial circulation using transcranial Doppler and/or angio-CT or MR-angiography. All patients with a positive CT-scan and/or neurological symptoms had a preoperative accurate neurological evaluation. Moreover, among common anaesthesiological and systemic risk-factors, ischemic heart diseases (IHD) were specifically taken into consideration.

For the purposes of this study, two groups of patients were formed, based on cognitive status at baseline. Thirty one patients (group A) were defined as having dementia following a clinical interview based on the criteria of the DSM-IV-TR [16], while 43 patients (group B) were defined as not having any form of dementia. The cognitive ability of patients with dementia (group A) was classified as mildly impaired.
Although a large number of patient characteristics were evaluated at baseline, the sample size of this study was too small for running all the preoperative comparisons related to these variables. Thus, the number of group variables (e.g., perioperative characteristics) has been reduced to laterality and severity of stenosis, presence of IHD, positive cerebral CT-scan, gender, age, and level of education, besides cognitive status. Preoperatively, 38 patients presented unilateral stenosis, 29 contra lateral highdegree stenosis, and 7 contra lateral internal carotid artery (ICA) occlusion. Eighteen patients had a stenosis of about $75 \%, 41$ a stenosis of $80 \%-90 \%$ and 15 a severe stenosis greater than $90 \%$. Thirty patients had ischemic heart diseases (IHD), 62 patients had a positive ipsilateral CT scan and 12 a positive contra lateral CT scan.

Table 1 presents the characteristics of patients classified in two groups based on cognitive status (e.g., presence $v s$. absence of mild dementia). Patients in Group A were older $(p=.01)$ and with a lower level of education $(p=.03)$ than patients in Group B. Nevertheless, age and education were not taken into consideration as potential confounding variables in between-group comparisons, as cognitive function scores were a-priori adjusted for age and education, based on normative data.

\section{Surgical procedure}

All the interventions were performed under general anaesthesia using the same anaesthesiological protocol (preanesthesia with benzodiazepine per os + atropine, induction with fentanest $2.5 \mu \mathrm{g} . \mathrm{kg}^{-1}$, propofol 2-2.5 mg.kg-1, norcuron $0.08-0.1 \mathrm{mg}^{-\mathrm{kg}^{-1}}$, maintenance with $\mathrm{O}_{2}=40 \%$ in air, sevoflurane 2 vol\%). After induction, a $0.1 \mathrm{mg} / \mathrm{kg}$ dexamethasone bolus was administered intravenously, thus about 10

Table 1. - Demographic and preoperative characteristics of patients

\begin{tabular}{|c|c|c|c|}
\hline & $\begin{array}{c}\text { Group A } \\
(\boldsymbol{n}=\mathbf{3 1})\end{array}$ & $\begin{array}{c}\text { Group B } \\
(n=43)\end{array}$ & Comparisons \\
\hline $\begin{array}{r}\text { Gender - male } \\
\text { female }\end{array}$ & $\begin{array}{l}21(68 \%) \\
10(32 \%)\end{array}$ & $\begin{array}{l}30(70 \%) \\
13(30 \%)\end{array}$ & $\mathrm{Chi}^{2}=0.03, p=.86$ \\
\hline Age (years) & $73.42 \pm 6$ & $69 \pm 8$ & $\mathrm{~F}_{(1,73)}=6.73, p=.01$ \\
\hline Education (years) & $5.06 \pm 2.7$ & $7 \pm 3$ & $\mathrm{~F}_{(1,73)}=5.01, p=.03$ \\
\hline IHD & $13(42 \%)$ & $17(40 \%)$ & $\mathrm{Chi}^{2}=0.003, p=.95$ \\
\hline $\begin{array}{l}\text { ICA - Left } \\
\text { Right }\end{array}$ & $\begin{array}{l}17(55 \%) \\
14(45 \%)\end{array}$ & $\begin{array}{l}22(51 \%) \\
21(49 \%)\end{array}$ & $\mathrm{Chi}^{2}=0.65, p=.42$ \\
\hline $\begin{array}{l}\text { ICA stenosis: } \\
\text { Monolateral } \\
\text { Bilateral } \\
\text { Contralateral occlusion }\end{array}$ & $\begin{array}{c}17(55 \%) \\
10(32 \%) \\
4(13 \%)\end{array}$ & $\begin{array}{c}21(49 \%) \\
19(44 \%) \\
3(7 \%)\end{array}$ & $\mathrm{Chi}^{2}=1.15, p=.56$ \\
\hline $\begin{array}{l}\text { Degree of ICA stenosis: } \\
75-80 \% \\
80-90 \% \\
>90 \%\end{array}$ & $\begin{array}{c}6(19 \%) \\
19(62 \%) \\
6(19 \%)\end{array}$ & $\begin{array}{l}12(28 \%) \\
22(51 \%) \\
9(20 \%)\end{array}$ & $\mathrm{Chi}^{2}=0.88, p=.64$ \\
\hline $\begin{array}{l}\text { Positive Cerebral CT-scan: } \\
\text { Ipsilateral } \\
\text { Contralateral }\end{array}$ & $\begin{array}{c}27(84 \%) \\
4(16 \%)\end{array}$ & $\begin{array}{c}35(81 \%) \\
8(19 \%)\end{array}$ & $\mathrm{Chi}^{2}=0.71, p=.54$ \\
\hline
\end{tabular}


min before clamping approximately $100 \mathrm{~mL}$ of mannitol $18 \%$ and a 2500 I.U. intravenous bolus of heparin were infused.

Cerebral monitoring was performed by measuring the stump-pressure during test clamping, and by continuous measure of the regional cerebral oxygen saturation $\left(\mathrm{rSO}_{2}\right)$ in the bilateral frontal-parietal area with the use of Near-Infrared Spectroscopy (NIRS) utilizing the model INVOS 4100 A (Somanetics Corp., Troy, MI). A De Bakey - USCI intraluminal shunt was routinely inserted in patients whose preoperative CT brain scan showed extensive ischemic lesions, or upon a reduction in the NIRS value of over $20 \%$ of the preclamping value in patients with a negative CT scan or with lacunae or small lesions.

CEA was performed prevalently with a short incision from common carotid to the bulb, repaired with a running suture; longer incision was repaired with a polyester patch.

At the end of the suture, a completion intraoperative colour Doppler ultrasound was performed in all the patients utilizing an ESAOTE AU5 scanning machine, with a $7.5 / 10 \mathrm{MHz}$ IOE $13 \mathrm{~A}$ probe, recording the peak systolic velocity (PSV) and the end diastolic velocity (EDV) in the treated internal carotid artery after the B-mode evaluation.

\section{Measures}

Cognitive function was assessed by means of the Mini Mental State Examination [17], a 30-points global cognitive function test which is widely used in clinical settings due to its practicality. The MMSE items cover orientation (time and space), memory, attention, language, calculation and prassic ability. A 2006 review [18] of 581 articles using screening tools for dementia shows that the MMSE has high sensitivity and specificity in outpatients older than 65 years when age-and education-specific cut-offs are used. The MMSE was used at baseline, while at 3-months follow-up the 26-points Italian telephone version of the MMSE (Itel-MMSE) [19] was preferred, because it proved to enhance reassessment if returning to the clinic is difficult for the patient [20]. The 26-points version of the MMSE has shown high reliability and validity [21]. A strong correlation $(\mathrm{r}=$ 0.85) observed for all patients between Itel-MMSE and MMSE was confirmed also in subgroups of patients with Alzheimer's disease, vascular dementia, frontotemporal dementia, and remained statistically significant also for patients with hearing loss and mild aphasia [20-24]. Total scores of the two MMSE versions correlated strongly also for very mildly $(r=0.77)$ and mildly $(r=0.79)$ demented [22]. Scores of both the MMSE and the Itel-MMSE were corrected for age and level of education, based on the Italian normative studies [22,23].

MMSE scores at pre-test were also calculated based on the 26-points scoring format, to allow within group comparisons (i.e. pre- vs. follow-up testing scores) on cognitive function.

Correction for preoperative anxiety is a common recommended solution to control for biases of study [25]. Nevertheless, instead of anxiety, we included a measure of depression at baseline to be used as covariate because it has been associated with increased risk of cognitive impairment, independent of under- lying vascular disease [26]. Depression was assessed through the Zung Depression Rating Scale (ZDRS) [27], a well-known and world-widely used self-rating scale for the measurement of depression, with acceptable validity and reliability [28]. ZDRS consists of 20 items that cover affective, psychological, and somatic symptoms of depression.

All psychological tests were administered by a psychologist, specifically trained.

\section{Statistical analysis}

ANCOVA tests using the General Linear Model were performed to compare baseline characteristics of study groups; cognitive score change over time, patterns of change between-groups, and impact of cognitive function and depression at baseline on change of cognition.

Differences were considered significant at a level of $\mathrm{p}<.05$. Statistical analyses were performed with SPSS 13.0 software package.

\section{Results}

Perioperatively, in 43 cases we performed a simple running suture of the arteriotomy, in 38 a polyester preclotted patch. Only $17 \%$ of patients presented a decrease $>20 \%$ of regional oxygen saturation measured by NIRS during clamping, 20\% presented a stump-pressure $<50 \mathrm{mmHg}$, but an intraluminal USCI shunt was inserted in $22 \%$ cases due to large cerebral ischemic lesions.

The patient with the detached patch experienced a distal embolism from the pseudo aneurysm during carotid dissection, with consequent siphon occlusion, however she was asymptomatic at the awakening, but presented a worsening of cognitive function and depression; another patient was treated for an early post-operative thrombosis of the endarterectomized site with the complete recovery of neurological symptoms and with an improvement of cognitive function. At discharge, patients were asymptomatic with a potency rate of $98.7 \%$. At 3 and 6 months follow-up all patients were asymptomatic without restenosis.

Preoperative comparisons were performed on cognitive function scores between groups of patients, based on the 30-points MMSE; mean scores of the 26-points Itel-MMSE version were also reported. In particular, gender, presence of dementia, laterality of stenosis, range of stenosis severity, presence of IHD, and positive cerebral CT-scan were used as between groups factors, while age and level of education were introduced as covariates. Tests of between subjects effects showed that:

a) None of the interactions between groups factors and covariates were statistically significant;

b) Groups A and B were obviously statistically different in cognition, independent of the other factors or covariates taken into consideration, $\mathrm{F}_{(1,76)}=164.34, \mathrm{p}<.0001$, group $\mathrm{A}$ mean $=20.26$ \pm 2.55 , group $\mathrm{B}$ mean $=25.98 \pm 1.41$. At a cutoff of 20-21, the 30-points MMSE was found to discriminate between clinical diagnosed cases of dementia (based on DSM-VI criteria) from healthy control with a sensitivity of above .90 and a specificity of .80 [19]. 
Mean score of patients at pre-test based on the 26-points MMSE were as follows: group A mean $=14.39 \pm 2.74$, group $\mathrm{B}$ mean $=18.74 \pm$ 1.27. Group A mean scores were between those obtained in the same test by patients classified a priori (classes of Clinical Dementia Rating) as very mildly and mildly demented in the Italian psychometric study of the ItelMMSE (i.e., $15.30 \pm 4.24$, and $12.39 \pm 4.16$, respectively) [23].

c) Presence of IHD was associated with a difference in cognitive function, measured with the 30-point MMSE, independent of other factors and covariates, $\mathrm{F}=6.97, \mathrm{p}=.01$; IHD presence mean $=24.13 \pm 3.05$, IHD absence mean $=$ $23.17 \pm 3.45$ (26-points MMSE mean scores: $17.63 \pm 2.64$, and $16.40 \pm 3.15$, respectively).

d) No differences were found on cognition between subgroups as related to gender, age, level of education, laterality and severity of stenosis, and positive cerebral CT-scan.

The cognitive function scores were then analyzed with time of measurement (i.e, pre-test vs. 3months follow-up) as a within-subjects factor using a 26-points MMSE format for both measurements. Presence of dementia and presence of IHD were used as between groups factors, while 30point MMSE and Depression scores at baseline were introduced as covariates. Presence of dementia, although a priori classified as mildly severe, was introduced because part of the aim of this study was to test whether change on cognitive function after CEA would be equivalent in patients classified as having or not dementia. Presence of IHD was used because preoperative testing showed a significant difference on the MMSE scores between patients with and without IHD. The 30-points MMSE score at baseline was introduced as covariate based on significant difference between groups A and B founded at pre-test. The Depression score at baseline was introduced as covariate to control for biases due to the influence of depression on cognitive test performance before surgery. Results showed that none of the interactions between factors and covariates were statistically significant, thus their effects on within groups analyses were taken as independent from each other.
The main effect of time of measurement was significant, $\mathrm{F}=14.19, \mathrm{p}=.0003$.

Among the covariates, baseline 30-points MMSE scores interacted significantly with the repeated measure, $\mathrm{F}=18.17, \mathrm{p}<.0001$. The difference between patients scores on pre-test and followup partly depended on initial cognitive function scores. Tests of within subjects effects are presented in Table 2.

None of the other independent variables (e.g. presence of dementia, IHD and depression at baseline) showed a significant effect on cognitive function change over time.

Estimated marginal means (e.g., adjusted 26points Itel-MMSE scores to what they would be if all patients scored the same at pre-test on both 30points MMSE and Depression) showed a significant mean difference of $-1.04, p=.002$ between pre-test and follow-up, with 95\% confidence interval for difference between -1.69 and -.38 . This result suggests a significant improvement in cognitive function 3 months after CEA. Estimated marginal means are presented in Table 3.

A graphic representation of change involving both groups A and B is presented in Figure 1. Thus, after controlling for the effects of both covariates, an improvement clearly emerged after CEA in both groups. It was greater, albeit not significantly, in group B than in group A.

\section{Discussion and conclusion}

Results from the literature on change in cognitive function after CEA are heterogeneous so that it's difficult to draw definitive conclusions. As the carotid endarterectomy is the most frequent operation in vascular surgery, the effect on cognitive function can be relevant, in particular if this treatment is associated with a decrease of cognitive function.

Many of the reported studies suffer from poor methodology [14]. To avoid some of the most frequent biases, we analyzed a homogeneous group formed by asymptomatic patients only, we controlled for the effects of variability in both cognitive function and depression at baseline, and we performed post-test at 3-months post treatment to avoid practice effects.

Table 2. - Tests of Within-Subjects Contrasts on 26-points MMSE scores

\begin{tabular}{|c|c|c|c|c|}
\hline Source & $\begin{array}{c}\text { Mean (sd) } \\
\text { pre-test }\end{array}$ & $\begin{array}{l}\text { Mean (sd) } \\
\text { follow-up }\end{array}$ & $\mathbf{F}$ & $p$ \\
\hline Pre $v s$. follow-up & $16.88(2.99)$ & $18.27(1.99)$ & 14.19 & .0003 \\
\hline Pre $v s$. follow-up* pre-MMSE & & & 18.17 & .0001 \\
\hline Pre $v s$. follow-up* pre-Depression & & & .75 & .39 \\
\hline $\begin{array}{r}\text { Pre vs. follow-up* Dementia: Group A } \\
\text { Group B }\end{array}$ & $\begin{array}{l}14.39(2.74) \\
18.74(1.27)\end{array}$ & $\begin{array}{l}17.42(2.57) \\
18.27(2.31)\end{array}$ & .25 & .62 \\
\hline $\begin{array}{ll}\text { Pre } v s . \text { follow-up } * \text { IHD: } & \text { Group IHD } \\
\text { Group no-IHD }\end{array}$ & $\begin{array}{l}17.63(2.64) \\
16.40(3.15)\end{array}$ & $\begin{array}{l}17.77(2.28) \\
18.00(2.30)\end{array}$ & 1.54 & .22 \\
\hline Pre-test $v s$. follow-up* Dementia * IHD & & & 1.21 & .28 \\
\hline
\end{tabular}


Table 3. - Estimates Marginal Means of 26-points Itel-MMSE scores

\begin{tabular}{lllccc}
\hline & Mean & Std. Error & 95\% Confidence Interval \\
\hline \multirow{2}{*}{ Group A } & & & Lower Bound & Upper Bound \\
& Pre-test & $16.94(\mathrm{a})$ & .32 & 16.11 & 17.57 \\
& Follow-up & $17.52(\mathrm{a})$ & .58 & 16.36 & 18.67 \\
Group B & Pre-test & $16.84(\mathrm{a})$ & .25 & 16.34 & 17.34 \\
& Follow-up & $18.20(\mathrm{a})$ & .46 & 17.29 & 19.11 \\
\hline a. Covariates appearing in the model are evaluated at the following values: pre-test 30-points MMSE $=23.51$, pre-test Depression \\
$=48.15$.
\end{tabular}

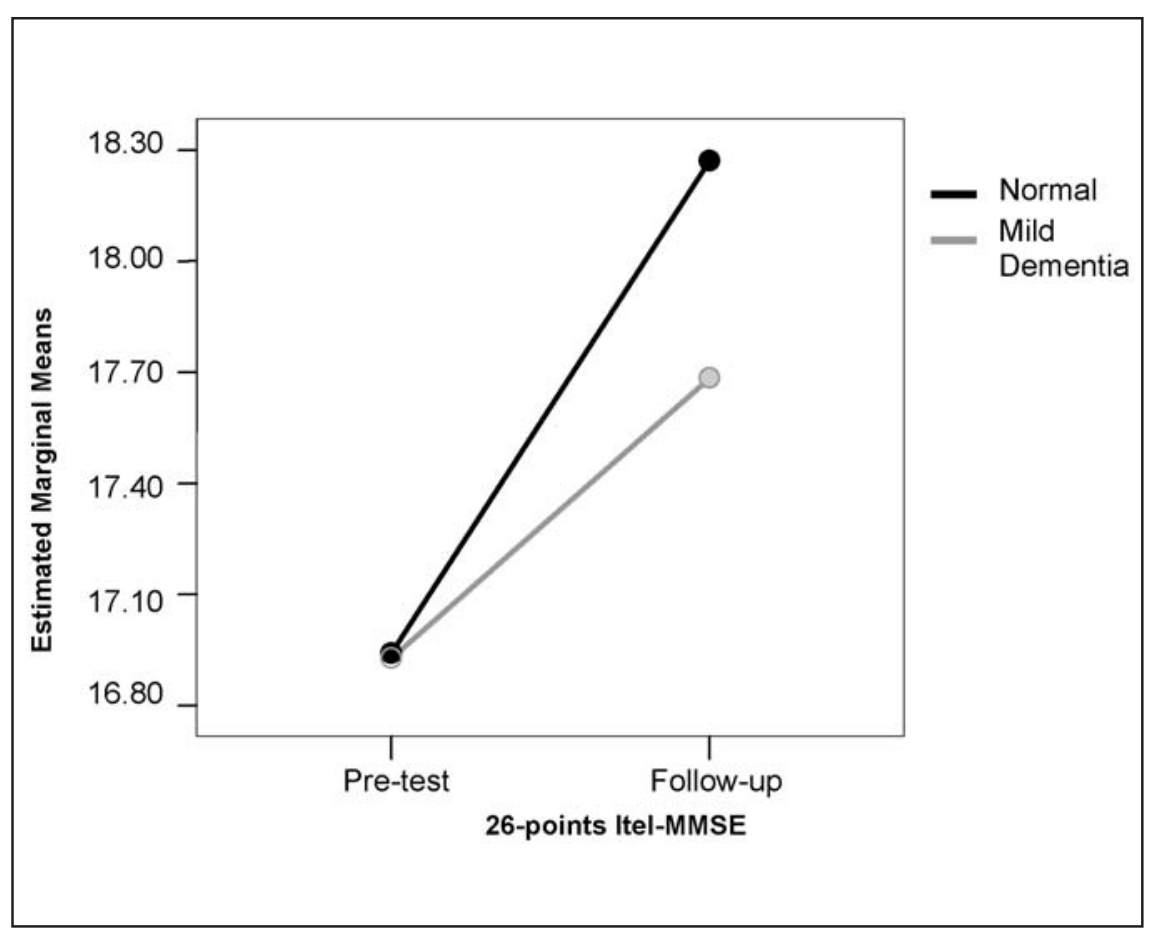

Figure 1. - Estimated Marginal Means of 26-points Itel-MMSE scores change between pre-test and 3months follow-up.

Even a silent ischemic lesion at brain CT could be worse during clamping getting greater or symptomatic; an increase of the ischemic area is potential and has been observed, moreover the relationship between ischemic lesions and dementia is recognized. For this reason we analyzed the role of preoperative lesions at CT-scan in the development of vascular dementia and their association with a change or a worsening of cognitive function of this group of patients. In our sample there were no relationships between preoperative positive CT-scan, preoperative cognitive impairment and postoperative modifications. A limit of our research is that ischemic areas were evaluated by CT-scan and not with more sophisticated technique, such as diffusion-MR. However, following the criteria for the diagnosis of Vascular Dementia stated by the consensus National Institute of Neurological Disorder and Stroke-Association Internationale pour Recherche et l'Enseignment en Neuroscience (NINDSAIREN), that include in the aetiology even sub cortical ischemic lesions and Binswanger's disease [29], for this study we have considered "positive" even the more evident modifications of the white matter, that can be related to chronic cerebral hypo perfusion and may be a risk factor for cognitive deficits [6].

New ischemic lesions can be one of the causes of post-operative decline of cognitive functions. Cerebral regional ischemia during clamping cannot be completely excluded both with neurological assessment under local anaesthesia and with the monitoring techniques commonly utilized. In our sample the evaluation of cerebral ischemia was based on NIRS, however we shunted even patients without oxygen decrease but with large ischemic areas, to reduce the risk to compromise the ischemic area that frequently surround an infarction. The modalities adopted for shunting, based on these parameters, avoided clamping-related neurological deficits. Using this policy the incidence of clamping ischemia in our experience is very low, reporting a mortality plus stroke rate of $0.9 \%$ in a sample of more than 2000 CEA, being the perioperative strokes almost all caused by post-operative thrombosis. Moreover, a brain-CT control randomly performed in asymptomatic operated cases or CT-scan obtained in patients complaining headache in the first post-operative hours failed to show new ischemic lesions.

Some researchers have evaluated micro embolism during CEA by transcranial Doppler (TCD) observing a small degree of micro embolism during and immediately following CEA being not able to find significant associations between any cognitive change or deterioration score and presence or number of intraoperative and/or postoperative emboli [24]. On the contrary other authors found relationships between greater than 10 particulate emboli detected during the dissection phase of CEA and a deterioration in cognitive function in the early postoperative period in seven out of eight patients in a sample of 100 consecutive CEA [30]. 
Probably, only diffusion-MR or more sophisticated techniques will confirm the association between post-procedural ischemic lesions and cognitive deterioration.

The anaesthetic management under general anaesthesia could be an important factor, as different anaesthetic drugs can decrease cerebral oxygen consumption, and a dose-related increase in cerebral blood volume can be obtained with others, as suggested by higher cerebral oxyhemoglobin and total haemoglobin levels [31]. For this reason we decided to standardize the anaesthesiological protocol in our sample to avoid a further bias.

The severity of the treated stenosis, the potency of the contra lateral carotid artery, the efficacy of extra cranial-intracranial pathway, are all factors that theoretically could be associated with an impairment of cerebral regional blood flow. Patients with impaired CVR generally demonstrate greater flow changes on declamping, probably due to impaired auto-regulation when full perfusion pressures are restored. In the study of Fearn et al [32], these patients gained the greatest improvements in attention scores at 8 weeks, perhaps because these were impaired by poor cerebral perfusion initially.

In our study we did not measure CVR; nevertheless, we could assess the collateral pathway measuring the stump pressure and the regional oxygen saturation after clamping. A significant increase of cognitive function was observed in $78.6 \%$ of patients with a stump-pressure $<50 \mathrm{mmHg}$ and in $72.4 \%$ in patients with stump-pressure $\Rightarrow 50$ $\mathrm{mmHg}$. No statistically significant difference was observed in patients with a NIRS $\mathrm{rSO}_{2}$ decrease greater than $20 \%$ after clamping.

Postoperative vascular complications can be responsible for cognitive decline; the patient with embolic occlusion showed a decrease of her cognitive functions, on the contrary, the prompt treatment of the post-operative thrombosis observed in this sample allowed avoiding permanent neurological deficits and ischemic brain changes at CT-scan; moreover the patient showed a cognitive improvement at follow-up.

Another point taken into consideration was the side of the stenosis, as previous studies showed that cerebrovascular ischemic episodes involving the left carotid vascular territory are associated with greater risk of cognitive impairment and post-stroke dementia. Even this parameter did not result discriminating in our sample even if the incidence of dementia was higher in the patients operated for a stenosis of the left ICA $(46.3 \%)$ than for the right one $(37.5 \%)$. However, it might be argued that, as MMSE is sensitive to left hemisphere lesions, these findings might reflect the bias of the instrument [33].

Finally, another limit of the present study was the absence of a control group [10]. In our opinion, the comparison of two different vascular techniques could be useful, but it should be better a comparison between the effects of carotid surgery under local versus general anaesthesia performed in the same department, or a comparison of carotid surgery with another surgical treatment of the neck in general surgery.
In conclusion, this study investigated cognitive change in patients with carotid diseases under well defined conditions, taking into consideration differences related to individual characteristics. In other studies neuropsychological benefits from CEA were found for patients in specific conditions, related to a lower level of complete cerebral perfusion [33, 34].

In this study improvement of cognition following CEA involved all patients, independent of the presence of mild dementia at baseline and of other individual differences and preoperative conditions. For these patients CEA seemed to offer significant benefit in neuropsychological terms that might represent a positive change in the quality of their daily-life.

\section{Riassunto}

L'obiettivo di questo studio è stato quello di valutare eventuali cambiamenti nella funzione cogniti$v a$ in seguito ad endarterectomia carotidea (CEA).

Il campione comprende 31 pazienti affetti da demenza e 43 pazienti senza alcun sintomo di demenza. La funzione cognitiva, il livello di depressione, la lateralità e la gravità della stenosi, $i$ risultati della tomografia cerebrale, la presenza di ischemie cardiovascolari sono stati misurati prima dell'intervento chirurgico in 74 pazienti asintomatici. La funzione cognitiva è stata misurata nuovamente tre mesi dopo la CEA usando un breve test standardizzato.

Dopo aggiustamento multivariato per la funzione cognitiva e la sintomatologia depressiva pre-operatoria, la funzione cognitiva è migliorata tre mesi dopo la CEA sia in pazienti con, sia in pazienti senza demenza.

La CEA può offrire ai pazienti con stenosi carotidea qualcosa in più della riduzione del rischio di ictus, indipendentemente dalla loro condizione di deterioramento cognitivo preoperatorio.

\section{ABBREVIATIONS}

CAS $=$ Carotid Artery Stenting

CEA $=$ Carotid Endarterectomy

$\mathrm{CT}=$ Computer Tomography

ICA = Internal Carotid Artery

IHD $=$ Ischemic Heart Diseases

MMSE = Mini Mental State Examination

\section{References}

1. North American Symptomatic Carotid Endarterectomy Trials Collaborators. Beneficial effect of carotid endarterectomy in symptomatic patients with high-grade carotid stenosis. N Engl J Med 1991; 325: 445-53.

2. European Carotid Surgery Trialists' Collaborative Group. MRC European Carotid Surgery Trial: interim results for symptomatic patients with severe or mild carotid stenosis. Lancet 1991; 337: 1235-1243.

3. Executive Committee for Asymptomatic Carotid Atherosclerosis Stenosis. Endarterectomy for asymptomatic carotid artery stenosis. JAMA 1995; 273: 1421-8.

4. MCR Asymptomatic Carotid Surgery Trial (ACST) Collaborative Group. Prevention of disabling and fatal strokes by successful carotid endarterectomy in patients without recent neurological symptoms: randomised controlled trial. Lancet 2004; 363: 1491. 
5. Kikumoto O. Clinical study on depressive state following stoke. Seishin Shinkeigaku Zasshi 1990; 92(7): 411-34.

6. Bakker FC, Kliyn CJM, Schinkel A et al. Cognitive disorders in patients with occlusive disease of the carotid artery: A systematic review of the literature. $J$ Neurol 2000; 247: 669-676.

7. Iadecola $\mathrm{C}$, Gorelick $\mathrm{PB}$. Converging pathogenic mechanisms in vascular and neurodegenerative dementia. Stroke 2003; 34: 335-337.

8. Desmond DW, Moroney JT, Sano M, Stern Y. Incidence of dementia after stroke. Stroke 2002; 33: 2254-2260.

9. Johnston SC, O'Meara ES, Manolio TA, Lefkowitz D, O'Leary DH, Goldstein S, Carlson MC, Fried LP, Longstreth WT Jr. Cognitive impairment and decline are associated with carotid artery disease in patients without clinically evident cerebrovascular disease. Ann Intern Med 2004; 140: 237-247.

10. Irvine.CD, Gardner FV, Davies AH, Lamont PM. Cognitive Testing in Patients Undergoing Carotid Endarterectomy. Eur J Vasc Endovasc Surg 1998; 15: 195-204.

11. Lunn, S, Crawley F, Harrison MJ, Brown MM, Newman SP. Impact of carotid endarterectomy upon cognitive functioning. A systematic review of the literature. Cerebrovasc Dis 1999; 9(2): 74-81.

12. Haynes CD, Gideon DA, King GD, Dempsey RL. The improvement of cognition and personality after carotid endarterectomy. Surgery 1976; 80(6): 699-704.

13. Aleksic M, Huff W, Hoppmann J, Purkrop R, Brunkwall J. Cognitive function remains unchanged after endarterectomy of unilateral internal carotid artery stenosis under local anaesthesia. Eur J Vasc Endovasc Surg 2006; 31: 616-621.

14. Sciarroni L, Gremigni P, Pedrini L. Psychological impact of carotid endarterectomy: a review of the studies. Monaldi Arch Chest Dis 2007; 68: 170-177.

15. Falleti, K. (2006). Practice effects associated with the repeated assessment of cognitive function using the $\mathrm{Cog}$ State Battery at 10 min, one week, and one month test-retest intervals. Neuropsychology, Development and Cognition: Journal of Clinical and Experimental Neuropsychology, 28A, 1095-1112.

16. Othmer E, Othmer SC. The Clinical Interview using DSM-IV-TR. American Psychiatric Association, Washington, DC, 2002.

17. Folstein M, Folstein S, McHugh PR. Mini Mental State. A practical method for grading the cognitive state of patients for clinicians. J Psychiatr Res. 1975; 12: 189-198.

18. Harvan JR, Cotter V. An evaluation of dementia screening in the primary care setting. J Am Acad Nurse Pract 2006; 18(8): 351-360.

19. Ferrucci L, Del Lungo I, Guralnik JM, et al. Is the telephone interview for cognitive status a valid alternative in persons who cannot be evaluated by the Mini Mental State Examination? Aging 1998; 10(4): 332-338.
20. Newkirk LA, Kim JM, Thompson JM, Tinklenberg JR, Yesavage JA, Taylor JL. Validation of a 26-point telephone version of the Mini-Mental State Examination. $J$ Geriatr Psychiatry Neurol 2004; 17(2): 81-87.

21. Roccaforte WH, Burke WJ, Bayer BL, Wengel SP. Validation of a telephone version of the mini-mental state examination. J Am Geriatr Soc 1992; 40(7): 697-702.

22. Metitieri T, Geroldi C, Pezzini A, Frisoni GB, Bianchetti A, Trabucchi M. The Itel-MMSE: an Italian telephone version of the Mini-Mental State Examination. Int J Geriatr Psychiatry. 2001; 16(2): 166-7.

23. Magni E, Binetti G, Bianchetti, Rozzini R, Trabucchi M. Mini-mental state examination: a normative study in Italian elderly population. Eu J Neurol 1996; 3: 1-5.

24. Measso G, Cavarzeran F, Zappalà G, et al. Il Mini Mental State Examination: studio normativo di un campione random della popolazione italiana. Devel Neuropsychol 1993; 9: 77-85.

25. Bossema ER, Brand N, Moll FL, Ackerstaff RGA, van Doornen LJP. Perioperative Microembolism is not Associated with Cognitive Outcome Three Months after Carotid Endarterectomy. Eur J Vasc Endovasc Surg 2005; 29: 262-268.

26. Barnes DE, Alexopoulos GS, Lopez OL, Williamson JD, Yaffe K. Depressive symptoms, vascular disease, and mild cognitive impairment: findings from the Cardiovascular Health Study. Arch Gen Psychiatry 2006; 63(3): 273-279.21.

27. Zung WWK. A Self-Rating Depression Scale. Arch Gen Psychiatry 1965; 12: 63-70

28. Biggs JT, Wylie LT, Ziegler VE. Validity of the Zung Self-rating Depression Scale. Br J Psychiatry 1978; 132: 381-385.

29. Román GC. Vascular Dementia: Distinguishing Characteristics, Treatment, and Prevention. J Am Geriatr Soc 2003; 51: S296-S304.

30. Gaunt ME, Martin PJ, Smith JL, et al. Clinical relevance of intraoperative embolization detected by transcranial Doppler ultrasonography during carotid endarterectomy: a prospective study of 100 patients. Br J Surg. 1994; 81(10): 1435-9.

31. Iwasaki K, Nomoto Y, Ishiwata M, Yokota T, Ogawa R. Vital capacity induction with $8 \%$ sevoflurane and $\mathrm{N}_{2} \mathrm{O}$ causes cerebral hyperemia. J Anesth 2003; 17: 3-7.

32. Fearn SJ, Hutchinson S, Riding G, Hill-Wilson G, Wesnes $\mathrm{K}$, McCollum CN. Carotid endarterectomy improves cognitive function in patients with exhausted cerebrovascular reserve. Eur J Vasc Endovasc Surg 2003; 26(5): 529-536.

33. Bo M, Massaia M, Speme S, et al. Risk of Cognitive Decline in Older Patients After Carotid Endarterectomy: An Observational Study. J Am Geriatr Soc 2006; 54: 932-936.

34. Jacques S, Garner JT, Tager R, Rosenstock J, Fields T. Improved cognition after external carotid endarterectomy. Surg Neurol 1978; 10(4): 223-225. 